OPEN ACCESS

Edited by: Atul Malhotra, Monash University, Australia

Reviewed by: Madison Claire Badawy Paton, Cerebral Palsy Alliance, Australia

Deepak Chawla,

Government Medical College and

Hospital, India

*Correspondence: JianHua Fu

fujh1830@163.com

Specialty section: This article was submitted to Neonatology,

a section of the journal

Frontiers in Pediatrics

Received: 27 March 2021 Accepted: 02 August 2021 Published: 27 August 2021

Citation:

Huang X and Fu J (2021) Association Between Assisted Reproductive

Technology and White Matter Injury in

Premature Infants: A Case-Control

Study. Front. Pediatr. 9:686670

doi: $10.3389 /$ fped.2021.686670

\section{Association Between Assisted Reproductive Technology and White Matter Injury in Premature Infants: A Case-Control Study}

\author{
Xuejiao Huang and JianHua Fu* \\ Department of Pediatrics, Shengjing Hospital of China Medical University, Shenyang, China
}

Objectives: Whether there is a link between assisted reproductive technology (ART) and brain damage in premature infants remains unclear. The aim of this study was to determine whether premature infants conceived by ART are at a greater risk of developing white matter injury (WMI), as detected by magnetic resonance imaging (MRI) or diffusion-weighted imaging (DWI) within 14 days, than those naturally conceived (NC).

Methods: A retrospective case-control study was conducted on singleton premature infants with a gestational age of $\geq 28$ weeks and $<34$ weeks delivered between 2017 and 2019 at Shengjing Hospital, China Medical University. This study included 638 live births that were stratified into case group $(n=218)$ and control group $(n=420)$, depending on the presence or absence of WMI. The exposure proportion of ART was compared between the case and control groups, and a logistic regression model was used to identify whether ART was an independent risk factor for WMI.

Results: In the univariate analysis, the exposure proportion of ART conception was higher in cases than in controls (12.84 vs. $7.38 \%, p=0.024)$. According to the multivariable analysis, after adjustment for other variables, the association between ART and WMI remained significant (1.82; 95\% confidence interval, 1.04-3.21; $P=0.038$ ).

Conclusions: Singleton premature infants conceived by ART have a higher risk of WMI than NC infants. Given that ART is an independent risk factor for WMI in premature infants, more attention should be paid to neurodevelopmental outcomes in this group.

Keywords: assisted reproductive technology, brain injury, premature infants, diffusion weighted imaging, white matter injury

\section{INTRODUCTION}

Since the birth of the first in vitro fertilization (IVF)-conceived infant in 1978, assisted reproductive technology (ART) has become one of the primary methods to treat infertility. In recent years, the proportion of newborns conceived by ART has been increasing. In developed countries, the proportion of live births after ART can reach 1.5-5.9\% $(1,2)$. Assisted reproductive technology involves ovulation induction, acquisition and storage of the sperm and ovum, in vitro fertilization, intracytoplasmic sperm injection (ICSI), and in vitro culture of the fertilized zygote, which may affect the offspring (3). Although the majority of offspring conceived by ART demonstrate 
comparable health with naturally conceived (NC) children (4), some studies have indicated that ART increases the risk of adverse neonatal outcomes, such as preterm delivery, low birth weight, small-for-gestational-age (SGA), and birth defects (2-6). Furthermore, although previous studies have also reported the effects of ART on offspring growth and metabolic diseases, nervous system development, cognitive and psychosocial development, reproductive function, and cancer risk, they have not reached a unified conclusion $(7,8)$. It has been suggested that newborns conceived by ART are more likely to have adverse health outcomes than naturally conceived (NC) newborns, probably due to the high proportion of multiple pregnancies caused by ART (9). However, adverse health outcomes have also been reported in singleton births (10).

Prenatal brain development is a highly complex process and can easily be disturbed. It is noteworthy to mention that the manipulation of gametes and embryos during ART exposes them to altered environments during a critical period, which may subsequently impact brain development (11). White matter injury (WMI) is the major form of brain injury among premature infants (12), and some studies have reported that the incidence of WMI in infants with very low birth weight can be as high as $50 \%$ (13). Severe WMI can cause periventricular leukomalacia, with sequelae such as cerebral palsy, cognitive and behavioral abnormalities, audiovisual dysfunction, and epilepsy. Of note, some studies have observed that ART is associated with poor neurodevelopment, including cerebral palsy, epilepsy, and intellectual disability (14-16), but almost no studies mention the relationship between ART and WMI. We speculate that WMI is an important mediator between ART and adverse neurodevelopmental outcomes.

Therefore, the aim of this study was to determine the association between the use of ART and the risk of WMI detected by magnetic resonance imaging (MRI) and diffusion-weighted imaging (DWI); this study also aimed to determine whether ART is an independent risk factor for WMI. We hypothesized that ART would be associated with an increased risk of WMI.

\section{METHODS}

\section{Population}

This retrospective case-control study was conducted on singleton premature infants treated between January 2017 and December 2019 at the first neonatal intensive care unit of our institution. All singleton premature infants with a gestational age (GA) of $\geq 28$ weeks and $<34$ weeks who underwent head MRI and DWI within the first 2 weeks after birth were included. Because of the retrospective study design, the clinical data of only preterm infants $<34$ weeks could be collected for comparison, necessitating the exclusion of late preterm infants from this study. The exclusion criteria were as follows: (a) congenital brain malformations; (b) brain damage due to severe cerebral hemorrhage or inherited metabolic diseases; (c) vanishing twin pregnancies; and (d) incomplete medical records. The infants were stratified into case and control groups, depending on the presence or absence of WMI. The study protocol was approved by the ethical committee of Shengjing Hospital Affiliated to China Medical University (ethical code: 2021PS524K).

\section{MRI Acquisition and Diagnosis of WMI}

All babies relied on natural sleep to cooperate with the MRI and DWI sequence examinations of the head when they were clinically stable. The MRI scan was performed using a Philips Intera Achieva 3.0T superconducting MR instrument, and the scan parameters were as follows: T1WI sequence, TR/TE $=200$ $\mathrm{ms} / 2.3 \mathrm{~ms}$, matrix $=224 \times 162$, field of view $=180 \times 150$ $\times 89 \mathrm{~mm}^{3}$, section thickness $=5 \mathrm{~mm}$; T2WI: TR/TE $=5,000$ $\mathrm{ms} / 80 \mathrm{~ms}$, matrix $=240 \times 135$, field of view $=180 \times 150 \times 90$ $\mathrm{mm}^{3}$, section thickness $=5 \mathrm{~mm}$; DWI: TR $/ \mathrm{TE}=3,500 \mathrm{~ms} / 63 \mathrm{~ms}$, matrix $=112 \times 112$, field of view $=180 \times 180 \times 89 \mathrm{~mm}^{3}$, section thickness $=5 \mathrm{~mm}$. Two neuroradiologists who were blinded to the type of conception evaluated all MRI scans.

WMI was diagnosed following Cornette's criteria and divided into punctate white matter injury (PWMI) and diffuse white matter injury (DWMI), based on the MRI and DWI results within the first 2 weeks after birth. PWMI manifests as a point, cluster, and linear DWI high signal at the centrum semiovale or periventricular area, with or without a T1-high signal and T2low signal. DWMI manifests as varying hyperintensity ranges on DWI in the white matter around the lateral ventricle and involves the deep periventricular, central, and subcortical white matter (17).

\section{Data Collection}

Completed demographic and clinical data were extracted from the medical records. The neonate's sex, GA, birth weight, 1- and 5-min Apgar scores, conception method, patent ductus arteriosus (PDA), and the use of invasive ventilation were recorded. The mother's information included the type of delivery, age, perinatal steroid administration, premature rupture of membranes (PROM), chorioamnionitis, gestational hypertension, and gestational diabetes. ART was defined as infants conceived using standard IVF or ICSI.

\section{Statistical Analyses}

All data were classified as follows: sex (male vs. female), GA ( $<32$ vs. $\geq 32$ weeks), birth weight ( $<1,500$ vs. $\geq 1,500 \mathrm{~g})$, smallfor-gestational age (SGA; Yes vs. No), asphyxia (Yes vs. No), PDA (Yes vs. No), invasive ventilation (Yes vs. No), ART (Yes vs. No), mother's age ( $<35$ vs. $\geq 35$ years), type of delivery (natural or cesarean), prenatal steroid administration (Yes vs. No), PROM (Yes vs. No), chorioamnionitis (Yes vs. No), gestational hypertension (Yes vs. No), and gestational diabetes (Yes vs. No). The data are expressed as the number of cases and the percentage [n (\%)], and were compared using the Chisquare test. Univariable logistic regression was conducted to estimate crude association between mother and infant variables and odds of WMI. Variables with $P$-value $\leq 0.15$ were considered as potential significant determinants of WMI and were included in multivariable logistic regression. Multicollinearity between the independent variables was assessed by studying the variance inflation factor. Data were analyzed using the SPSS version 25.0 at 0.05 significance level. 


\section{RESULTS}

\section{Population}

There were 1,114 singleton premature infants with a GA of $\geq 28$ and $<34$ weeks, of which 476 infants were excluded (Figure 1). These excluded infants comprised the following: (a) 359 infants failed to complete head MRI within 14 days; (b) 71 with incomplete medical records; (c) 33 with severe cerebral hemorrhage or inherited metabolic diseases; (d) nine cases of vanishing twin pregnancies; and (e) four cases with congenital brain malformations. Eventually, a total of 638 patients were available for analysis, which included 218 cases and 420 controls.

\section{Univariate Analyses of Baseline Variables of Premature Infants in the Case and Control Groups}

The infants of the case group were more likely to have asphyxia (31.65 vs. $22.38 \%, p=0.011$ ) and require invasive ventilation (43.12 vs. $29.29 \%, p<0.001$ ). The case group had a higher exposure proportion of ART conception (12.84 vs. $7.38 \%, p=$ 0.024; Table 1).

\section{Univariate Analyses of Baseline Variables of Mothers in the Case and Control Groups}

A greater proportion of mothers in the case group than in the control group had PROM (44.95 vs. 33.10\%, $p=$ 0.003 ) and gestational diabetes (29.36 vs. $22.14 \%, p=0.045$ ); however, a lower proportion of mothers in the case group had cesarean delivery $(60.55$ vs. $74.76 \%, p<0.001)$ and gestational hypertension $(20.18$ vs. $31.67 \% p=0.002)$ than those in the control group (Table 2).

\section{Multivariate Analyses of Mother and Neonate Variables Associated With WMI}

After adjusting for the influence of confounding factors, ART conception was identified as an independent risk factor for WMI. After adjusting for the effects of SGA, asphyxia, PDA, invasive ventilation, cesarean, PROM, gestational hypertension, and gestational diabetes, the odds ratio of ART conception was 1.82 (95\% confidence interval: 1.04-3.21; Table 3).

\section{DISCUSSION}

ART has been available for 40 years, and people are increasingly concerned about the possible adverse effects of this technology on the health of mothers and babies. Previous studies on the health risks of children conceived through ART have focused mainly on the impact of ART on birth defects, and the research on ART and its neurodevelopmental risk on offspring was insufficient. Previous studies have shown that ART is associated with poor neurodevelopmental outcomes. An Australian cohort study observed an increased risk of cerebral palsy in singletons conceived with ART (14). In addition, studies have observed that children conceived by ART have an increased risk of intellectual disability and epilepsy $(15,16)$. Cerebral palsy, epilepsy, and cognitive behavioral abnormalities are serious sequelae of WMI; therefore, we speculate that WMI may be an important mediator between ART and poor neurological performance.

To the best of our knowledge, only few previous studies have investigated the impact of ART on WMI in preterm infants. In our study, regardless of whether univariate or multivariate analysis was performed, we found that ART is associated with WMI in preterm infants, confirming that ART is an independent risk factor for WMI in preterm infants. However, we did not follow up these children and, therefore, our study only provides a potential partial explanation of the association between ART and poor neurodevelopmental outcomes.

There are many potential mechanisms by which ART may be related to WMI, such as the effects of fertility hormone therapies used during ART, micromanipulation involved in ART procedures, and prenatal and perinatal complications related to ART treatment. Kalra et al. believe that during the routine ART superovulation stimulation process, the mother's internal environment will change, and that these changes

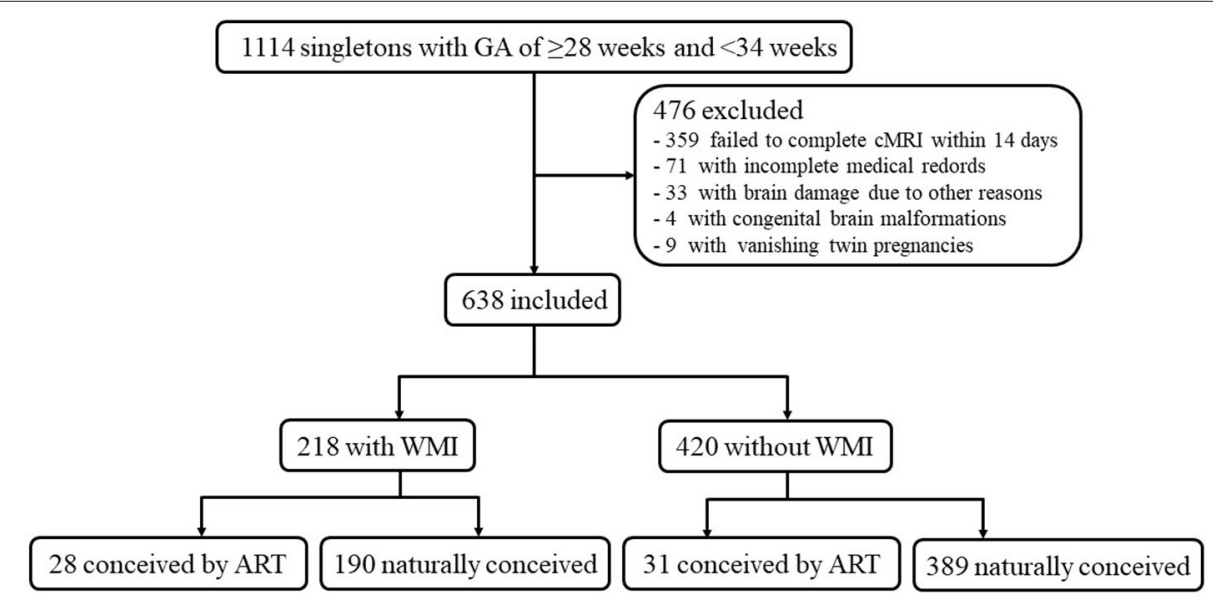

FIGURE 1 | Participant flowchart. 
TABLE 1 | Univariate analyses of baseline of premature infants in the case and control groups.

\begin{tabular}{|c|c|c|c|c|}
\hline \multirow[t]{2}{*}{ Variable } & \multicolumn{2}{|c|}{ WMI } & \multirow[t]{2}{*}{ OR $(95 \% \mathrm{Cl})$} & \multirow[t]{2}{*}{$P$-value } \\
\hline & $\begin{array}{c}\text { No } \\
(n=420)\end{array}$ & $\begin{array}{c}\text { Yes } \\
(n=218)\end{array}$ & & \\
\hline \multicolumn{5}{|l|}{ Sex } \\
\hline Girl $(n, \%)$ & $170(40.48)$ & $81(37.16)$ & $\begin{array}{c}\text { Reference } \\
1.15(0.82-1.61)\end{array}$ & 0.416 \\
\hline Boy $(n, \%)$ & 250 (59.52) & 137 (62.84) & & \\
\hline \multicolumn{5}{|l|}{ GA } \\
\hline$<32$ weeks $(n, \%)$ & 137 (32.62) & $82(37.61)$ & $\begin{array}{c}\text { Reference } \\
1.25(0.89-1.75)\end{array}$ & 0.208 \\
\hline$\geq 32$ weeks $(n, \%)$ & $283(67.38)$ & 136 (62.39) & & \\
\hline \multicolumn{5}{|l|}{ Birth weight } \\
\hline$<1500 \mathrm{~g}(n, \%)$ & 76 (18.10) & 39 (17.89) & $\begin{array}{c}\text { Reference } \\
0.99(0.64-1.51)\end{array}$ & 0.949 \\
\hline$\geq 1500 \mathrm{~g}(n, \%)$ & 344 (81.90) & $179(82.11)$ & & \\
\hline \multicolumn{5}{|l|}{ SGA } \\
\hline No $(n, \%)$ & 370 (88.10) & 201 (92.20) & $\begin{array}{c}\text { Reference } \\
0.63(0.35-1.11)\end{array}$ & 0.109 \\
\hline Yes $(n, \%)$ & $50(11.90)$ & $17(7.80)$ & & \\
\hline \multicolumn{5}{|l|}{ Asphyxia } \\
\hline No $(n, \%)$ & 326 (77.62) & 149 (68.35) & $\begin{array}{c}\text { Reference } \\
1.61(1.11-2.32)\end{array}$ & 0.011 \\
\hline Yes $(n, \%)$ & 94 (22.38) & 69 (31.65) & & \\
\hline \multicolumn{5}{|l|}{ PDA } \\
\hline No $(n, \%)$ & 347 (82.62) & $166(76.15)$ & $\begin{array}{c}\text { Reference } \\
1.49(1.00-2.22)\end{array}$ & 0.051 \\
\hline Yes $(n, \%)$ & $73(17.38)$ & $52(23.85)$ & & \\
\hline \multicolumn{5}{|l|}{ Invasive ventilation } \\
\hline No $(n, \%)$ & 297 (70.71) & $124(56.88)$ & $\begin{array}{c}\text { Reference } \\
1.83(1.30-2.57)\end{array}$ & $<0.001$ \\
\hline Yes $(n, \%)$ & 123 (29.29) & $94(43.12)$ & & \\
\hline \multicolumn{5}{|l|}{ ART } \\
\hline No $(n, \%)$ & 389 (92.62) & $190(87.16)$ & $\begin{array}{c}\text { Reference } \\
1.85(1.08-3.17)\end{array}$ & 0.024 \\
\hline Yes (n, \%) & $31(7.38)$ & $28(12.84)$ & & \\
\hline
\end{tabular}

GA, gestational age; SGA, small-for-gestational-age; PDA, patent ductus arteriosus; $A R T$, assisted reproductive technology.

can affect embryo transfer, trophoblast cell implantation, and placenta formation, thereby causing early embryo development retardation (18). The placenta seems to be more vulnerable after ART treatment. Studies have shown that there is a significant increase in the expression of $\mathrm{NF \kappa B}$ in ART placental tissue (19), and the upregulation of NFKB has been confirmed to be related to the pathogenesis of WMI $(20,21)$. In addition, in the critical early period of brain development, fetal steroid hormones are believed to play a role in the epigenetic fetal programming mechanism. In ART, the ovaries can produce estradiol in response to injected gonadotropins, exposing the embryo to supraphysiological levels of estradiol, directly impacting fetal growth, cell differentiation, and gene expression $(22,23)$. In addition, due to the particularity of intervention methods, ART involves unnatural conception processes such as ovulation
TABLE 2 | Univariate analyses of baseline of mothers in the case and control groups.

\begin{tabular}{|c|c|c|c|c|}
\hline \multirow[t]{2}{*}{ Variable } & \multicolumn{2}{|c|}{ WMI } & \multirow[t]{2}{*}{ OR $(95 \% \mathrm{Cl})$} & \multirow[t]{2}{*}{$P$-value } \\
\hline & $\begin{array}{c}\text { No } \\
(n=420)\end{array}$ & $\begin{array}{c}\text { Yes } \\
(n=218)\end{array}$ & & \\
\hline \multicolumn{5}{|c|}{ Maternal age at child birth } \\
\hline$<35$ years & $318(75.71)$ & $157(72.02)$ & $\begin{array}{c}\text { Reference } \\
1.21(0.84-1.75)\end{array}$ & 0.310 \\
\hline$\geq 35$ years & $102(24.29)$ & $61(27.98)$ & & \\
\hline \multicolumn{5}{|c|}{ Type of delivery } \\
\hline Natural & $106(25.24)$ & $86(39.45)$ & $\begin{array}{c}\text { Reference } \\
0.52(0.37-0.74)\end{array}$ & $<0.001$ \\
\hline Cesarean & $314(74.76)$ & $132(60.55)$ & & \\
\hline \multicolumn{5}{|c|}{ Prenatal steroid administration } \\
\hline No & $163(38.81)$ & $95(43.58)$ & $\begin{array}{c}\text { Reference } \\
0.82(0.59-1.14)\end{array}$ & 0.244 \\
\hline Yes & 257 (61.19) & $123(56.42)$ & & \\
\hline \multicolumn{5}{|l|}{ PROM } \\
\hline No & $281(66.90)$ & $120(55.05)$ & $\begin{array}{c}\text { Reference } \\
1.65(1.18-2.31)\end{array}$ & 0.003 \\
\hline Yes & $139(33.10)$ & $98(44.95)$ & & \\
\hline \multicolumn{5}{|c|}{ Chorioamnionitis } \\
\hline No & $353(84.05)$ & $176(80.73)$ & $\begin{array}{c}\text { Reference } \\
1.26(0.82-1.93)\end{array}$ & 0.292 \\
\hline Yes & 67 (15.95) & $42(19.27)$ & & \\
\hline \multicolumn{5}{|c|}{ Gestational hypertension } \\
\hline No & $287(68.33)$ & $174(79.82)$ & $\begin{array}{c}\text { Reference } \\
0.55(0.37-0.81)\end{array}$ & 0.002 \\
\hline Yes & $133(31.67)$ & $44(20.18)$ & & \\
\hline \multicolumn{5}{|c|}{ Gestational diabetes } \\
\hline No & $327(77.86)$ & $154(70.64)$ & $\begin{array}{c}\text { Reference } \\
1.46(1.01-2.12)\end{array}$ & 0.045 \\
\hline Yes & $93(22.14)$ & $64(29.36)$ & & \\
\hline
\end{tabular}

WMI, white matter injury; PROM, premature rupture of membranes.

TABLE 3 | Multivariate analyses of mother and neonate variables associated with WMI.

\begin{tabular}{lccc}
\hline Variable & OR & $\mathbf{9 5 \%} \mathbf{C l}$ & $\boldsymbol{P}$-value \\
\hline SGA & 0.68 & $0.36-1.28$ & 0.231 \\
Asphyxia & 1.55 & $1.03-2.34$ & 0.037 \\
PDA & 1.32 & $0.87-2.02$ & 0.192 \\
Invasive ventilation & 1.63 & $1.11-2.40$ & 0.012 \\
ART-conceived & 1.82 & $1.04-3.21$ & 0.038 \\
Cesarean delivery & 0.57 & $0.39-0.83$ & 0.003 \\
PROM & 1.57 & $1.08-2.28$ & 0.019 \\
Gestational hypertension & 0.81 & $0.51-1.30$ & 0.384 \\
Gestational diabetes & 1.29 & $0.87-1.92$ & 0.201
\end{tabular}

SGA, small-for-gestational-age; PDA, patent ductus arteriosus; PROM, premature rupture of membranes.

induction and gamete manipulation. These manipulations may interfere with epigenetic stability from different aspects (3). Epigenetics is defined as hereditary changes in gene expression 
without alterations in DNA sequence (24). It has been confirmed in animal models that the expression of miRNAs miR-122, and miR-144 and miR-211, involved in the regulation of neuronal migration and differentiation, were downregulated in the brains of offspring exposed to superovulated environment (22). In addition, one study observed altered DNA methylation patterns at specific genomic loci in bloodspot tests of newborn infants (25). Therefore, the relationship between WMI and ART has a specific pathophysiology, and the specific mechanism underlying this pathophysiology needs further study.

The main advantage of this study is that all research participants were singleton premature infants, which controls the confounding influence of multiple births and preterm birth on WMI to a certain extent. In addition, the case and control groups had different exposures to hypertension and diabetes during pregnancy, but this potential confounding effect was adjusted through multivariable logistic regression.

However, this study has some limitations. Because only fewer babies are conceived with ART, we could not investigate the impact of different kinds of ART on WMI alone. In addition, we could not identify the infants who were conceived only with ovulation induction or intrauterine insemination; therefore, they are included in non-ART. If these treatments are also associated with an increased risk of WMI, our risk estimates may be small. However, there is limited literature in this area. Owing to clinical instability, some infants did not complete the head MRI examination within 2 weeks, which may have introduced selection bias. There remains considerable gaps in the literature on the impact of ART on the neurodevelopment of offspring, and greater work needs to be done in the future. Welldesigned prospective studies with large sample size need to be conducted to further verify the conclusions of our study, control for as many potential confounders as possible-such as uterine placental blood circulation, and compare the effects of different ART protocols.

In summary, our study results show that premature infants conceived by ART are at an increased risk of WMI. This finding is relevant for providing appropriate information to parents considering assisted conception. Doctors providing ART

\section{REFERENCES}

1. Fa da. Silva SG, da Silveira MF, Bertoldi AD, Domingues MR, Dos Santos IDS. Maternal and child-health outcomes in pregnancies following assisted reproductive technology (ART): a prospective cohort study. BMC Pregnancy Childbirth. (2020) 20:106. doi: 10.1186/s12884-020-2755-Z

2. Boulet SL, Kirby RS, Reefhuis J, Zhang Y, Sunderam S, Cohen B, et al. Assisted reproductive technology and birth defects among liveborn infants in Florida, Massachusetts, and Michigan, 2000-2010. JAMA Pediatr. (2016) 170:e154934. doi: 10.1001/jamapediatrics.2015.4934

3. Mani S, Ghosh J, Coutifaris C, Sapienza C, Mainigi M. Epigenetic changes and assisted reproductive technologies. Epigenetics. (2020) 15:12-25. doi: 10.1080/15592294.2019.1646572

4. Morin SJ, Seli E. Assisted reproductive technology and origins of disease: The clinical realities and implications. Semin Reprod Med. (2018) 36:195-203. doi: 10.1055/s-0038-1677048

5. Schieve LA, Meikle SF, Ferre C, Peterson HB, Jeng G, Wilcox LS. Low and very low birth weight in infants conceived with use of assisted reproductive need to be informed of the potential risks of the technology so that they can strictly grasp its indications. Neonatologists need to consider the health risks of ART on premature infants and pay attention to their nervous system development outcomes. In addition, this finding needs confirmation in larger studies and further research is necessary to investigate the underlying mechanism.

\section{DATA AVAILABILITY STATEMENT}

The original contributions presented in the study are included in the article/supplementary material, further inquiries can be directed to the corresponding author/s.

\section{ETHICS STATEMENT}

The studies involving human participants were reviewed and approved by the ethics committee of Shengjing Hospital Affiliated to China Medical University. Written informed consent from the participants' legal guardian/next of kin was not required to participate in this study in accordance with the national legislation and the institutional requirements.

\section{AUTHOR CONTRIBUTIONS}

$\mathrm{XJH}$ and JHF contributed to the study design. XJH performed the data collection and analysis and drafted the manuscript. JHF reviewed the manuscript. All authors have read and approved the final manuscript.

\section{FUNDING}

This study was primarily funded by Key R\&D Guidance Plan Projects in Liaoning Province (2020JH1/10300001).

\section{ACKNOWLEDGMENTS}

We thank all of the participants of this study. technology. N Engl J Med. (2002) 346:731-7. doi: 10.1056/NEJMoa 010806

6. Davies MJ, Moore VM, Willson KJ, Van Essen P, Priest K, Scott H, et al. Reproductive technologies and the risk of birth defects. N Engl J Med. (2012) 366:1803-13. doi: 10.1056/NEJMoa1008095

7. Berntsen S, Söderström-Anttila V, Wennerholm UB, Laivuori H, Loft A, Oldereid NB. et al. The health of children conceived by ART: 'the chicken or the egg?'. Hum Reprod Update. (2019) 25:137-58. doi: 10.1093/humupd/dmz001

8. Balayla J, Sheehy O, Fraser WD, Séguin JR, Trasler J, Monnier P, et al. Neurodevelopmental outcomes after assisted reproductive technologies. Obstet Gynecol. (2017) 129:265-72. doi: 10.1097/AOG.0000000000001837

9. Picaud JC, Chalies S, Combes C, Mercier G, Dechaud H, Cambonie G. Neonatal mortality and morbidity in preterm infants born from assisted reproductive technologies. Acta Paediatr. (2012) 101:846-51. doi: 10.1111/j.1651-2227.2012.02713.x

10. Liberman RF, Getz KD, Heinke D, Luke B, Stern JE, Declercq ER, et al. Assisted reproductive technology and birth defects: effects of subfertility 
and multiple births. Birth Defects Res. (2017) 109:1144-53. doi: 10.1002/bd r2.1055

11. Husen SC, Koning IV, Go ATJI, Groenenberg IAL, Willemsen SP, Rousian M, et al. IVF with or without ICSI and the impact on human embryonic brain development: the Rotterdam Periconceptional Cohort. Hum Reprod. (2021) 36:596-604. doi: 10.1093/humrep/deaa341

12. Back SA. White matter injury in the preterm infant: pathology and mechanisms. Acta Neuropathol. (2017) 134:331-49. doi: 10.1007/s00401-0171718-6

13. Agut T, Alarcon A, Cabañas F, Bartocci M, Martinez-Biarge M, Horsch S, et al. Preterm white matter injury: ultrasound diagnosis and classification. Pediatr Res. (2020) 87:37-49. doi: 10.1038/s41390-020-0781-1

14. Goldsmith S, Mcintyre S, Badawi N, Hansen M. Cerebral palsy after assisted reproductive technology: a cohort study. Dev Med Child Neurol. (2018) 60:73-80. doi: 10.1111/dmcn.13577

15. Hansen M, Greenop KR, Bourke J, Baynam G, Hart RJ, Leonard H. Intellectual disability in children conceived using assisted reproductive technology. Pediatrics. (2018) 142:e20181269. doi: 10.1542/peds.2018-1269

16. Sun Y, Vestergaard M, Christensen J, Zhu JL, Bech BH, Olsen J. Epilepsy and febrile seizures in children of treated and untreated subfertile couples. Hum Reprod. (2007) 22:215-20. doi: 10.1093/humrep/del333

17. Cornette LG, Tanner SF, Ramenghi LA, Miall LS, Childs AM, Arthur RJ, et al. Magnetic resonance imaging of the infant brain: anatomical characteristics and clinical significance of punctate lesions. Arch Dis Child Fetal Neonatal Ed. (2002) 86:F171-7. doi: 10.1136/fn.86.3.F171

18. Kalra SK, Ratcliffe SJ, Coutifaris C, Molinaro T, Barnhart KT. Ovarian stimulation and low birth weight in newborns conceived through in vitro fertilization. Obstet Gynecol. (2011) 118:863-71. doi: 10.1097/AOG.0b013e31822be65f

19. Zhong X, Jiang YZ, Liu P, He W, Xiong Z, Chang W, et al. Tolllike 4 receptor $/ \mathrm{NF \kappa B}$ inflammatory/miR-146a pathway contributes to the ART-correlated preterm birth outcome. Oncotarget. (2016) 7:72475-85. doi: 10.18632/oncotarget.11987

20. Su X, Yuan H, Cui H, Zhu H, Yun X, Tang W, et al. Effect of T helper cell $1 / \mathrm{T}$ helper cell 2 balance and nuclear factor- $\kappa \mathrm{B}$ on white matter injury in premature neonates. Mol Med Rep. (2018) 17:5552-6. doi: $10.3892 / \mathrm{mmr} .2018 .8511$
21. Zaghloul N, Kurepa D, Bader MY, Nagy N, Ahmed MN. Prophylactic inhibition of NF- $\kappa \mathrm{B}$ expression in microglia leads to attenuation of hypoxic ischemic injury of the immature brain. J Neuroinflammation. (2020) 17:365. doi: 10.1186/s12974-020-02031-9

22. Mainigi M, Rosenzweig JM, Lei J, Mensah V, Thomaier L, Talbot CC Jr, et al. Peri-implantation hormonal milieu: elucidating mechanisms of adverse neurodevelopmental outcomes. Reprod Sci. (2016) 23:785-94. doi: 10.1177/1933719115618280

23. Mainigi MA, Olalere D, Burd I, Sapienza C, Bartolomei M, Coutifaris C. Peri-implantation hormonal milieu: elucidating mechanisms of abnormal placentation and fetal growth. Biol Reprod. (2014) 90:26. doi: 10.1095/biolreprod.113.110411

24. Gjaltema RAF, Rots MG. Advances of epigenetic editing. Curr Opin Chem Biol. (2020) 57:75-81. doi: 10.1016/j.cbpa.2020. 04.020

25. Estill MS, Bolnick JM, Waterland RA, Bolnick AD, Diamond MP, Krawetz SA. Assisted reproductive technology alters deoxyribonucleic acid methylation profiles in bloodspots of newborn infants. Fertil Steril. (2016) 106:629-39. doi: 10.1016/j.fertnstert.2016.05.006

Conflict of Interest: The authors declare that the research was conducted in the absence of any commercial or financial relationships that could be construed as a potential conflict of interest.

Publisher's Note: All claims expressed in this article are solely those of the authors and do not necessarily represent those of their affiliated organizations, or those of the publisher, the editors and the reviewers. Any product that may be evaluated in this article, or claim that may be made by its manufacturer, is not guaranteed or endorsed by the publisher.

Copyright (C) 2021 Huang and Fu. This is an open-access article distributed under the terms of the Creative Commons Attribution License (CC BY). The use, distribution or reproduction in other forums is permitted, provided the original author(s) and the copyright owner(s) are credited and that the original publication in this journal is cited, in accordance with accepted academic practice. No use, distribution or reproduction is permitted which does not comply with these terms. 